\title{
An Analysis of the Statistics Content in Nepali School Textbooks
}

\author{
Dustin L. Jones \\ Sam Houston State University \\ DLJones@shsu.edu
}

\author{
Deepak Basyal \\ University of Wisconsin-Milwaukee \\ Basyal@uwm.edu
}

\begin{abstract}
To determine the nature and extent of the statistics content that Nepali students may learn in school, we examined mathematics textbooks for grades 4-10 from five different publishers. All of the tasks in each statistics chapter were examined, for a total of 1755 tasks across 35 textbooks. Each task was classified according to the phases of the statistical problem-solving process (formulate questions, collect data, analyze data, interpret results) that were addressed. Nearly every task required students to analyze data; the other phases were rarely addressed. Additionally, tasks addressing the analysis phase were coded according to analysis activities; the majority of these tasks required students to read a display and perform a mathematical calculation. For each series, at least two-thirds of the statistics tasks followed a similar worked example. Based on these findings, we offer recommendations for teachers, textbook writers, and the Curriculum Development Centre.
\end{abstract}

Keywords: Mathematics in Nepal, Mathematics Curriculum, Textbooks, Statistics Education

\section{Introduction}

To successfully make decisions, people need to appropriately understand, analyze, and interpret information and data. These activities are encompassed in the definition of statistics offered by the American Statistical Association (2019): "Statistics is the science of learning from data and of measuring, controlling, and communicating uncertainty." Recognizing that the study of statistics can prepare students to make informed decisions, governments and professional organizations have made recommendations and guidelines regarding statistics education. For example, in the United States, the authors of the Guidelines for Assessment and Instruction in Statistics Education (GAISE) Report state, "Every highschool graduate should be able to use sound statistical reasoning to intelligently cope with the requirements of citizenship, employment, and family and to be prepared for a healthy, happy, and productive life" (Franklin et al., 2007, p. 1). These guidelines are, at best, research-based recommendations from experts, as there is no national curriculum in the United States. On the other hand, in Nepal, the government mandates a national curriculum. The Ministry of Education $(2009,2012,2014)$ specifies the topics from statistics to be included in mathematics courses; these are placed in grades 4-10.

The curriculum framework in Nepal is interpreted by textbook writers and implemented by classroom teachers, with the goal of helping students become successful and productive members of society. Both the government (through the Curriculum Development Centre) and private entities produce textbooks. Although the topics are specified in the curriculum framework, variation may exist in how the topics are presented. In this study, we 
seek to identify and describe the statistics content that Nepali students may learn. Specifically, we focus on mathematics textbooks, and address the following research question: What is the nature and extent of the statistics content in mathematics textbooks for Nepali students? With respect to the nature of the statistics content, we categorize tasks (i.e., exercises and activities) according to the phases of the statistical problem-solving process that are addressed, and whether they follow similar worked examples. Regarding the extent of the statistics content, we determine the location of the statistics chapters within the books of each series. In the next section, we will provide a rationale for this study, based on prior research in mathematics and statistics education.

\section{Context and Rationale}

\section{Nepali Educational Context}

In order to achieve the national goal of educating the citizens of Nepal by streamlining curriculum, textbooks, and other instructional materials, the Curriculum Development Centre (CDC) was established in 1997 (Ministry of Education, 2010, p. 40). In 2007, the CDC published the National Curriculum Framework (NCF) 2007. Following this, the Ministry of Education published guidelines for each grade level and subject to meet NCF 2007. Table 1 contains the statistics topics that should be included in mathematics courses for grades 4-10 (Ministry of Education, 2009, 2012, 2014).

Table 1: Nepali Curriculum Guidelines for Statistics

\begin{tabular}{|c|c|c|}
\hline Grade & $\begin{array}{l}\text { Class } \\
\text { Periods }\end{array}$ & Course Expectations for Statistics Chapter \\
\hline 4 & 9 & $\begin{array}{l}\text { Get information by reading thermometer; Collect data such as age, height, } \\
\text { number of animals, pages of a book, etc.; Read and construct tables of } \\
\text { information; Draw a bar graph using graph paper; Plot ordered pairs on } \\
\text { graph paper (first quadrant only) }\end{array}$ \\
\hline 5 & 9 & $\begin{array}{l}\text { Draw a conclusion from tabulated information; Present simple informa- } \\
\text { tion on a graph; Plot ordered pairs on a graph (first quadrant only) }\end{array}$ \\
\hline 6 & 8 & $\begin{array}{l}\text { Collect data; Make and interpret tally marks; Read and construct frequen- } \\
\text { cy distribution and simple bar diagram }\end{array}$ \\
\hline 7 & 10 & $\begin{array}{l}\text { Read and construct cumulative frequency table and multiple bar diagram; } \\
\text { Differentiate between ungrouped and grouped data; Find mean of un- } \\
\text { grouped data }\end{array}$ \\
\hline 8 & 10 & $\begin{array}{l}\text { Find mean, median, mode, and range of ungrouped data; Read and con- } \\
\text { struct pie chart and line graph }\end{array}$ \\
\hline 9 & 13 & $\begin{array}{l}\text { Construct line graph, pie chart, histogram, and ogive; Read statistical } \\
\text { information from histogram and frequency curve; Find mean, median, } \\
\text { mode, and quartiles of ungrouped data; Compare statistics of various } \\
\text { groups }\end{array}$ \\
\hline
\end{tabular}


17 Transform raw data to grouped data; Compute mean, median, mode, and quartiles of grouped data; Analyze and draw conclusions based on central tendency of data

While the CDC supplied a series of textbooks that met the national curriculum, the NCF 2007 also allowed entities outside of the government to write textbooks to be used as additional materials, and also allowed private schools to use textbooks and curriculum materials. Since 1990, private schooling has expanded at a dramatic pace, both in terms of numbers of schools and a widening base of students (Caddell, 2007). The increase of private schools brought about demands for textbooks that were appropriate for different grade levels (Thapa, 2011). Many publishing companies entered the market with mathematics textbooks that claimed to meet the NCF 2007 expectations.

We consider the NCF 2007 as the intended curriculum (Lamichhane, 2017; Valverde, Bianchi, Wolfe, Schmidt \& Houang, 2002) for Nepal. The intended curriculum informs the development of textbooks, which are a part of the implemented curriculum. The textbooks that form the sample for this study were all approved by the CDC to be used as additional material for schools.

\section{Rationale for Examining Textbooks}

In classrooms across the world, mathematics teachers rely on textbooks as a primary resource for planning and implementing instruction (Robitaille \& Travers, 1992). This is no different in Nepal. In a UNESCO report (Wagley et al., 2008), teachers in Nepal report that mathematics teaching is "fully dependent" (p. 102) on the textbook, and "We never go out of the textbook" (p. 103). These statements about mathematical textbooks indicate the prominence of textbooks in mathematics classrooms in Nepal. Mainali and Heck (2017) observed that the mathematics textbooks are used as the ultimate means for teaching at Nepali government high schools. The Nepal School Sector Development Plan 2016-2023 reports that "many teachers and the general public consider textbooks to be the end-all and be-all of the curriculum and all teaching is therefore tied to these books, with only the memorisation of the text often being the result" (Ministry of Education, 2016). From this, we see that textbooks are the main resources for mathematics teachers and students in schools of Nepal. Teachers use the textbook to prepare lesson plans and assign homework; students use it to find definitions and worked examples, as well as for homework problems and helpful hints. To investigate the nature and extent of the statistics content that Nepali students learn, we examine the textbooks that they use.

The Nepali education system is relatively young; a national organized education system children started after the dawn of democracy in 1951 (Wood, 1959), and the first national curriculum appeared in 1971 (Ministry of Education, 1971). Therefore, it is not surprising to note that there has been very little effort in analyzing mathematics textbook in Nepal. There is a scarcity of research pertaining to mathematics textbook quality. To date, no systematic study of the statistical content of Nepali mathematics textbook has been carried out.

Prior Research on Statistics Content of Mathematics Textbooks 
While this is the first study of its kind for Nepali textbooks, other research has been conducted to analyze that statistics content of textbooks. We incorporate the work of Jones \& Jacobbe (2014) and Jones et al. (2015). Jones \& Jacobbe (2014) examined six university-level mathematics textbooks for prospective elementary teachers in the United States. Specifically, they identified sections containing statistics content and classified the tasks within those sections according to the phases of the statistical problem-solving process. According to Guidelines for Assessment and Instruction in Statistics Education (GAISE) Report: A Pre-K-12 Curriculum Framework (Franklin et al., 2007), these four phases are: Formulate Questions, Collect Data, Analyze Data, and Interpret Results. While tasks may address more than one phase, they found that at least $70 \%$ of the tasks for each textbook addressed the Analyze Data phase. In the present study, we also classify statistics tasks according to the phases of the statistical problem-solving process, using the rubric provided in the appendix of Jones \& Jacobbe (2014).

Jones et al. (2015) extended this work to examine the statistics content of school textbooks for students in grades 1-5 (typically, students aged 6 to 11 years). They examined series of U.S. textbooks (for grades 1 through 5) from five different publishers, and classified statistics tasks according to phases of the statistical problem-solving process. They further coded tasks addressing the Analyze Data phase (calling these analysis tasks) according to one or more Analysis Activities: Read a Display, Perform a Mathematical Calculation, Construct a Display or Use Other Statistical Reasoning. They found the majority of tasks in each series addressed the Analyze Data phase; for four of the five series, the percentage was greater than $90 \%$. Regarding Analysis Activities, between $75 \%$ and $95 \%$ of analysis tasks required students to Read a Display. The majority of analysis tasks in four of the five series required students to Perform a Mathematical Calculation, and $14 \%$ to $21 \%$ of analysis tasks required students to construct a display. In the present study, we examine series of school mathematics textbooks for Nepali students in grades 4-10, which overlaps the grade range in Jones et al. (2015). We use these same codes to classify each Analysis Activity, in order to determine the nature of analysis tasks.

\section{Methodology}

\section{Textbook Selection}

We selected five series of mathematics textbooks for our sample. Each series was approved by the CDC and currently used in Nepali schools. We examined the English version of the textbooks for students in grades 4-10. Therefore, our sample consisted of 35 textbooks, with seven textbooks from each of five publishers. The names of the textbook series are listed in Table 2. Throughout this paper, we will refer to the series by the publisher name: CDC, Ekta, Green, Prasiddha, and Vidyarthi. Full reference information for these textbooks is provided in the Appendix. 
Table 2: Textbooks in the Sample

\begin{tabular}{|l|l|}
\hline Publisher & Name of the series \\
\hline Curriculum Development Centre & My Mathematics (Grades 4-10) \\
Ekta Books & New Creative Mathematics (Grades 4-7) and Math- \\
& Plus (Grades 8-10) \\
Green Books & Green Mathematics (Grades 4-10) \\
Prasiddha Prakashan & Functional Mathematics (Grades 4-10) \\
Vidyarthi Prakashan & Perfect Mathematics (Grades 4-10) \\
\hline
\end{tabular}

We selected the CDC series for our sample because it was developed by the Government of Nepal. To identify other books for our sample, one of the researchers contacted teachers in various parts of Nepal. The other four series were selected based on recommendations from these mathematics teachers.

\section{Units of Analysis}

To address our research question, we use two units of analysis. To address the extent of statistics content, we use textbook pages in statistics chapters. Regarding the nature of statistics content, we use statistics tasks. These units are defined below.

Statistics chapter pages. In each textbook, we determined the total number of chapter pages in the textbook, i.e., pages containing materials from the chapters of the book. Pages at the beginning and end of the book containing non-chapter material (e.g., preface, table of contents, answers to exercises, index) are not considered chapter pages. Each book in our sample had a single chapter devoted to statistics; the pages therein are statistics chapter pages. Using page numbers, we determined the percentage of all chapter pages that were statistics chapter pages. The page numbers were also converted to percentiles, in order to determine the relative location in the textbook. For example, in a textbook with 240 chapter pages and statistics chapter pages numbered 180 to 208, we say there are 29 statistics chapter pages (180 to 208 , inclusive), about $12 \%(29 / 240)$ of the chapter pages are statistics chapter pages, and the location of the statistics chapter is from the $75^{\text {th }}(180 / 240)$ to the $87^{\text {th }}$ (approximately 208/240) percentile of chapter pages.

Statistics tasks. We identified all of the statistics tasks within the statistics chapter. Following the methodology of Jones and Jacobbe (2014) a statistics task was the "smallest marked division" (p. 6) of an exercise, problem, or activity related to statistics. Therefore, if item 3 had four parts (a, b, c, and d), each of $3 a, 3 b, 3 c$, and $3 d$ were considered separate tasks. If item 4 had only one part, it was considered a single task. Worked examples, where answers were provided in the textbook, were not considered statistics tasks. Statistics tasks that were coded as addressing the Analyze Data phase were called analysis tasks.

\section{Coding Scheme}

Each statistics task received codes related to the phases of the statistical problem- 
process that it addressed. A task coded as Analyze Data received a code for Analysis Activities. Finally, every task was coded according to whether it followed a similar worked example in that textbook. These codes, along with illustrative examples, are presented below.

Phases of the statistical problem-solving process. A statistics task received at least one code according to the phase(s) of the statistical problem-solving process that it addressed. These phases are Formulate Questions, Collect Data, Analyze Data, and Interpret Results. We used the rubric in Jones and Jacobbe (2014) to determine the phases of each task. A single task could receive multiple codes. Table 3 contains examples of statistics tasks for each of these four phases.

Table 3: Codes for Phase of the Statistical Problem-Solving Process

\begin{tabular}{|l|l|}
\hline Phase & Example task \\
\hline Formulate Questions & $\begin{array}{l}\text { Identify the genders of the first } 40 \text { newborns in a locality as either } \\
\text { quantitative or qualitative. (Ekta grade 7, p. 93) } \\
\text { In some local newspapers, the share prices of companies are } \\
\text { published five days a week. For three companies of your choice, } \\
\text { collect the prices of the shares for } 15 \text { days. (Ekta grade 10, p. 328) } \\
\text { The numbers of goals scored by a football team in a series of } \\
\text { matches during a particular season were: 14, 13, 6, 2, 1, 0, 9, 12, 11, } \\
\text { 7, 5, 12, 10, 8, 3. Find the median number of goals. In how many } \\
\text { matches did the team score goals more than the median? (Ekta grade } \\
8, \text { p. 179) } \\
\text { [Following an analysis of test results.] Do you conclude that the test } \\
\text { was difficult? (Ekta grade 6, p. 166) }\end{array}$ \\
\hline
\end{tabular}

Analysis activities. Each analysis task (i.e., statistics task that addressed the Analyze Data phase) received at least one code for Analysis Activity, as found in Jones et al. (2015): Read a Display, Perform a Mathematical Calculation, Construct a Display, or Use Other Statistical Reasoning. An analysis task may receive more than one code for Analysis Activity. Table 4 contains examples of analysis tasks for each type of Analysis Activity.

Table 4: Codes for Analysis Activity

\begin{tabular}{|l|l|}
\hline Analysis Activity & Example task \\
\hline Read a Display & $\begin{array}{l}\text { [A frequency table for number of students who did not do home- } \\
\text { work during one week is presented.] Which day did most of the } \\
\text { students do homework? (CDC grade 4, p. 107) }\end{array}$ \\
$\begin{array}{l}\text { Perform a Mathematical } \\
\text { Calculation } \\
\text { Construct a Display }\end{array}$ & $\begin{array}{l}\text { Find the range of the given data. } 12 \mathrm{~cm}, 15 \mathrm{~cm}, 19 \mathrm{~cm}, 14 \mathrm{~cm}, \\
10 \mathrm{~cm}, 8 \mathrm{~cm} 20 \mathrm{~cm}, 11 \mathrm{~cm}(\mathrm{CDC} \text { grade } 8, \mathrm{p} .154) \\
\text { Draw a bar graph to represent the height of students [presented } \\
\text { in a frequency table]. (CDC grade 4, p. 107) }\end{array}$
\end{tabular}


Use Other Statistical Reasoning
The following are the marks obtained in mathematics by 15 students of class 8 in district level examination: $45,46,67,78$, $85,92,49,65,79,58,59,45,67,85,78$, In how many ways the above data can be presented. Discuss in groups. (CDC grade 9 , p. 179)

Similar worked example. Each statistics task was also given a single code (yes or no) to indicate whether it followed a similar worked example in the textbook. An assignment of "yes" indicated that a worked example in the same textbook illustrated how to complete the exercise or problem. The worked example could list the steps in a procedure, or present a worked example with different numerical values.

\section{Inter-rater Reliability}

Both authors of this article independently identified and coded the statistics tasks in three textbooks from one series, and then discussed their codes. Whenever there was a difference in codes, the disagreements were discussed until 100\% agreement was reached on all tasks. This process was repeated, with researchers coding tasks in another set of 2 to 4 textbooks. After coding the tasks in 17 textbooks, the researchers had perfect agreement on more than $90 \%$ of the tasks before discussion. After discussing the disagreements, one researcher coded the tasks in the remaining 18 textbooks. The other researcher independently coded a random sample of tasks from these textbooks, and there was perfect agreement on more than $95 \%$ of the tasks. Again, all differences were discussed until agreement was reached on $100 \%$ of the statistics tasks.

\section{Statistics Pages}

\section{Results}

Each of the 35 textbooks contained a chapter related to statistics. Overall, we examined 599 statistics pages. As shown in Table 5, statistics chapters in textbooks for grades 4-6 tend to have fewer pages than those for grades 7-10.

Table 5: Number of Statistics Pages by Grade Level

\begin{tabular}{ccccc}
\hline & \multicolumn{4}{c}{ Number of Statistics Pages } \\
\cline { 2 - 5 } Grade & Minimum & Maximum & Mean & Median \\
\hline 4 & 7 & 13 & 10.6 & 11 \\
5 & 8 & 18 & 10.8 & 10 \\
6 & 6 & 11 & 8.8 & 8 \\
7 & 9 & 20 & 13.4 & 14 \\
8 & 13 & 33 & 23 & 23 \\
9 & 10 & 40 & 27.4 & 31 \\
10 & 20 & 33 & 25.8 & 23 \\
\hline
\end{tabular}

Note: Five textbooks were coded for each grade level.

Statistics pages are often located near the end of the textbook, usually in the final quarter of the book. One exception was the series of books published by Ekta, where the 
statistics chapter begins within the first half of the textbooks for grades 7 and 8 , and between the $50^{\text {th }}$ and $70^{\text {th }}$ percentiles of pages for grades 4,5 and 6 . Figure 1 displays the position of the statistics pages for each textbook. To compare the placement of the statistics pages across books with different numbers of pages, we report the data in terms of the percentile of pages. The horizontal line segments indicate the pages in the statistics chapter, and are grouped by publisher. The seven books for each publisher are represented in grade level order, with the textbook for grade 4 on top and grade 10 on the bottom. For example, the top line segment in the Ekta section indicates that the statistics pages of the grade 4 book lie between the $50^{\text {th }}$ and $60^{\text {th }}$ percentiles of pages; they are in the beginning of the second half of that text.

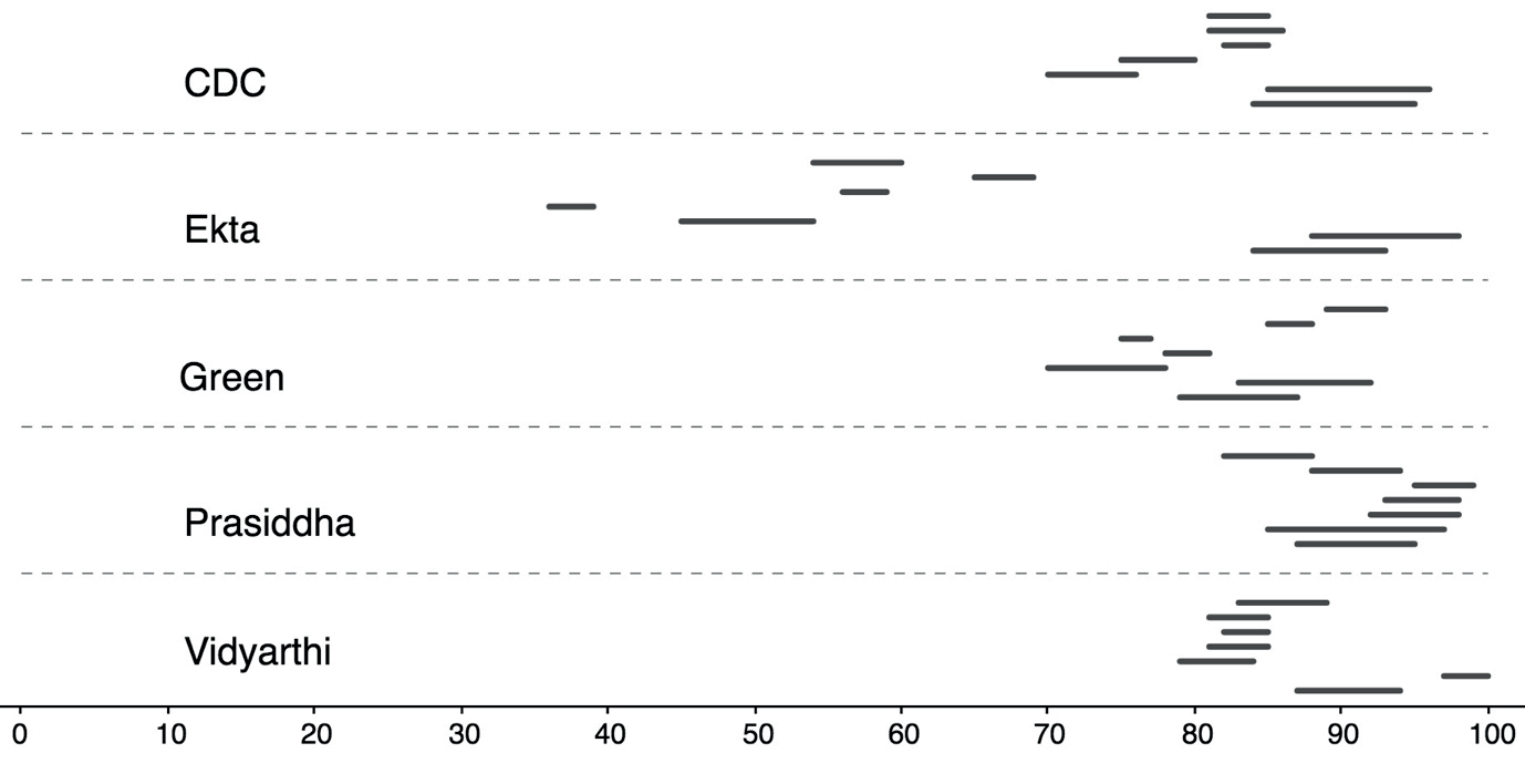

Location of Page as a Percentile

Figure 1: Location of statistics chapters in terms of the percentiles of pages

\section{Phases of the Statistical Problem-Solving Process}

We identified 1755 statistics tasks in the textbooks in our sample. As Table 6 shows, our sample included tasks that addressed each of the four phases of the statistical problemsolving process. Recall that a statistics task could be assigned multiple codes of this type.

Table 6: Number of Tasks Addressing Phases of the Statistical Problem-Solving Process

Phases of the Statistical Problem-Solving Process

\begin{tabular}{cccccc}
\cline { 3 - 5 } Publisher & $\begin{array}{c}\text { Number of } \\
\text { Tasks }\end{array}$ & $\begin{array}{c}\text { Formulate } \\
\text { Questions }\end{array}$ & Collect Data & Analyze Data & $\begin{array}{c}\text { Interpret Re- } \\
\text { sults }\end{array}$ \\
\hline CDC & 296 & 0 & 20 & 293 & 0
\end{tabular}




\begin{tabular}{cccccc}
\hline Ekta & 291 & 4 & 3 & 287 & 5 \\
Green & 342 & 0 & 10 & 342 & 0 \\
Prasiddha & 437 & 0 & 5 & 437 & 0 \\
Vidyarthi & 389 & 0 & 0 & 389 & 1 \\
\hline Overall & $\mathbf{1 7 5 5}$ & $\mathbf{4}$ & $\mathbf{3 8}$ & $\mathbf{1 7 4 8}$ & $\mathbf{6}$ \\
\hline
\end{tabular}

Almost all of these tasks addressed the Analyze Data phase (1748 out of 1755, or $99.6 \%$ of statistics tasks). Indeed, all of the tasks in the series by Green, Prasiddha, and Vidyarthi address Analyze Data. The other phases were not represented similarly in the five series; Formulate Questions was only addressed in the Ekta series, and Interpret Results was only addressed by the Ekta and Vidyarthi series. Additionally, Vidyarthi was the only series that contained no tasks addressing Collect Data.

\section{Analysis Activities}

With respect to analysis tasks, more than half of the tasks in each series require students to Read a Display. For four of the five series, more than half of the tasks require students to Perform a Mathematical Calculation. Analysis tasks could receive multiple codes of this type, so these percentages do not sum to $100 \%$. Figure 2 displays the percentage of analysis tasks for each series according to Analysis Activity.

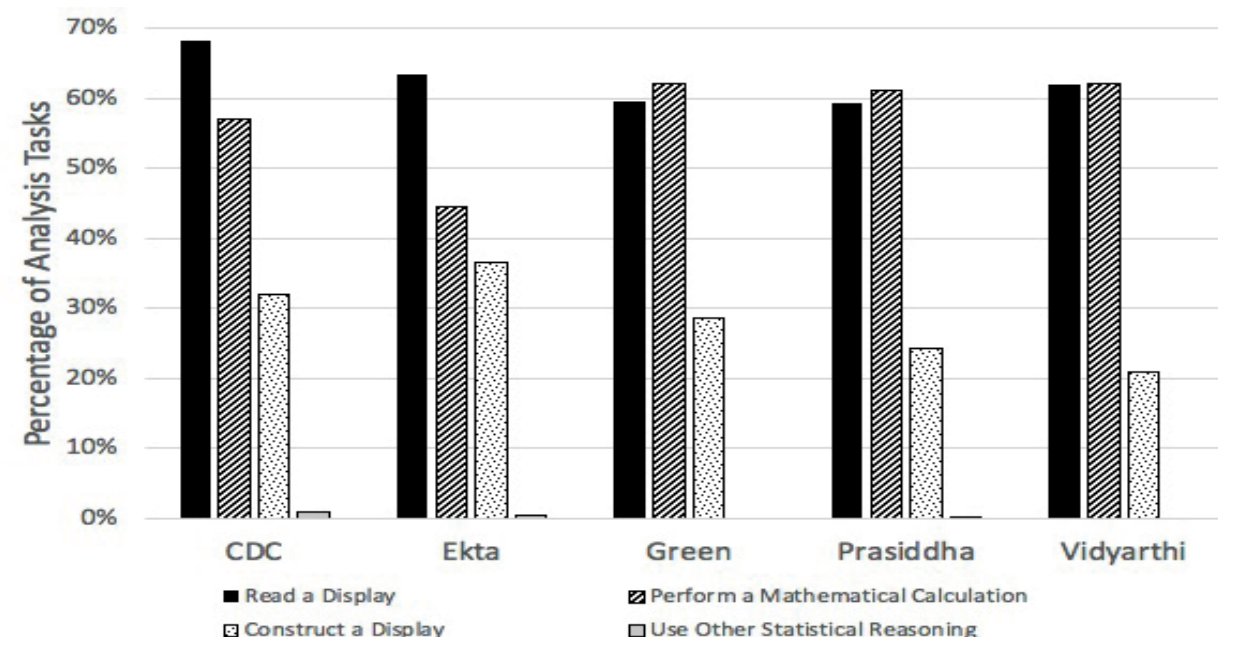

Figure 2. Distribution of Analysis Activity Codes, by Series

\section{Similar Worked Examples}

As shown in Figure 3, most of the statistics tasks were preceded by similar worked examples. Comparing the five series, the percentage of such tasks ranged from $70 \%$ of the statistics tasks in the Vidyarthi series to $95 \%$ of the statistics tasks in the Ekta series. 


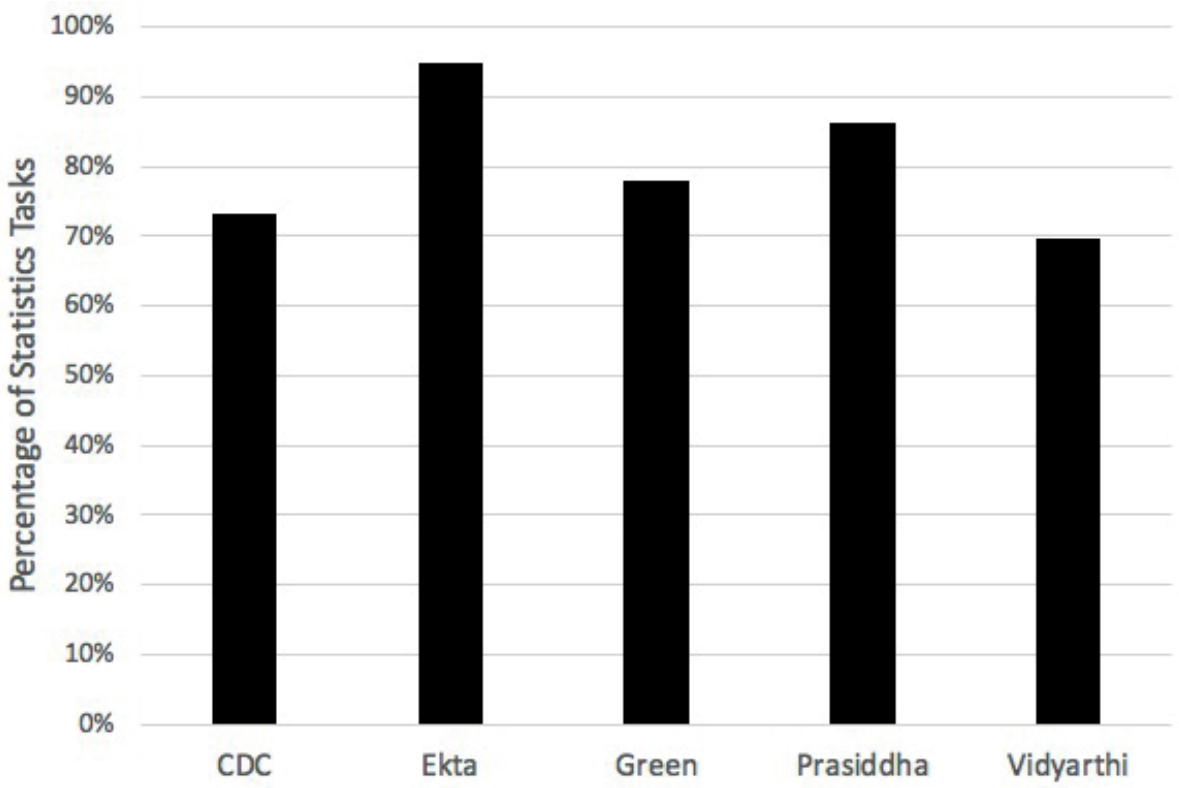

Figure 3. Statistics Tasks Preceded by Similar Worked Examples, by Series

\section{Discussion}

In light of these results, we return to the research question for this study: What is the nature and extent of the statistics content in mathematics textbooks for Nepali students? We first address the issue of the extent of statistics content. The results related to the number of statistics pages, and the location of statistics chapters within textbooks, show that statistics is present within all textbooks. While there is not a large number of pages devoted to statistics, the relative emphasis on statistics within textbooks appears to be similar to the relative emphasis on statistics within the NCF 2007 guidelines. With a required minimum of 180 to 192 days of school per year, the Ministry of Education $(2009,2012,2014)$ guidelines recommend that $5 \%$ to $10 \%$ of days be devoted to statistics topics; these percentages are similar to the percentages of textbook pages in statistics chapters. The placement of statistics chapters near the end of the textbook may reflect the placement of statistics within the guidelines (Ministry of Education, 2009, 2012, 2014). It may also be the case that some publishers are following the lead of the CDC series in the order and topics of textbook chapters. At the same time, the Nepali mathematics curriculum has been called "overloaded" with topics (Lamichhane, 2017, p. 95). It may be that statistics, with its small number of recommended days, is overlooked during the year.

Regarding the nature of the statistics content, we note that three of the four phases of the statistical problem-solving process are practically absent from textbooks. As in the study of U.S. series of textbooks (Jones et al., 2015), the majority of tasks addressed the Analyze Data phase, and the second most common phase addressed was Collect Data. Unlike the U.S. textbook series, there were Nepali series in our sample that did not address Formulate Questions or Interpret Results. Therefore, we find that Nepali textbooks do not present the full statistical problem-solving process. This, in turn, may lead students to a narrow view of 
statistics, concluding that it is solely related to the analysis of data.

The rank ordering of Analysis Activities across the analysis tasks in this study, with the most emphasis going toward Read a Display and then Perform a Mathematical Calculation, is similar to that of U.S. textbook series examined by Jones et al. (2015). It appears that, in both of these studies, textbooks present statistics as a field related to data visualization and mathematical formulas. While these two topics are a part of statistics, it is important to also consider the design of questions, types of variables, the process of data collection, and, perhaps most important, how to use graphical representations and mathematical formulas to make inferences and decisions.

The majority of statistics tasks were preceded by worked examples. While this textbook feature may aid students who are confused about how to complete a task, it can also reduce the cognitive demand of a task. When a worked example is present, completing a similar statistics task is reduced to following a procedure. In some cases, the procedure may not be accompanied by an explanation. This textbook feature also leads to an incomplete view of statistics as a collection of formulas and procedures. This view is likely reinforced by practices in some Nepali mathematics classrooms, "in which teachers are dispenser[s] of mathematical facts and knowledge and students are passive receivers" (Lamichhane, 2017, pp. 95-96).

\section{Implications}

These findings have implications for teachers, textbook writers, and the Curriculum Development Centre. Teachers should plan to address statistics during the school year. Furthermore, teachers should strive to incorporate activities where students participate in all phases of the statistical problem-solving process. This may require extending or modifying tasks that are found within the textbook.

Textbook writers should incorporate all phases of the statistical problem-solving process within statistics chapters. This requires including more tasks that address Formulating Questions, Collecting Data, and Interpreting Results. We are not calling for equal attention to each phase, as this may not be ideal. At the same time, ignoring a phase of the process is definitely not ideal. Additionally, textbook writers should include more tasks that do not mirror worked examples, but are still are accessible to students. This can promote creative reasoning, as opposed to imitative reasoning (Lithner, 2008).

Finally, the Curriculum Development Centre should be mindful of the current state of statistics within textbooks. Almost all of the statistics expectations in course guideline documents (Ministry of Education, 2009, 2012, 2014) address the Analyze Data phase; therefore it is not surprising that approved textbooks have a large emphasis on this phase. Perhaps future revisions of course guidelines could include all phases of the statistical problem-solving process. Indeed, national policymakers are in the best position to produce changes that will benefit all students in Nepal. As the textbooks are guided by the national curriculum, improving the curriculum would result in improved versions of textbooks that allow students to participate in the entire statistical problem-solving process.

\section{Further Research}

While this study describes the current state of the statistical content in Nepali 
mathematics textbooks, it does not produce a recommendation for ideal blend of tasks in terms of analysis activities, phases of the statistical problem-solving process, or even the presence of worked examples. Indeed, to date, we have not found any research publication with a theoretical stance on these issues. Furthermore, these theories must be interpreted and understood with respect to cultural and educational contexts (Pepin \& Haggarty, 2001). Future research efforts should focus on identifying the effects of the Nepali curriculum on student learning, perhaps through correlational studies (e.g., Törnroos, 2005) of textbook features and student achievement as measured by the Secondary Education Exam. Research such as this will help inform the development of a theoretically ideal textbook for Nepal. This research also opens an avenue for comparative analysis of the statistical content of Nepali textbooks with textbooks in other nations.

Overall, we find that Nepali students have opportunities to learn some statistical content when using these textbooks. The textbooks in this study may lead students to form an incomplete view of statistics that may not lead them to be fully prepared to make decisions based on data. Through the efforts of teachers, textbook writers, and national policymakers, this situation can be improved.

\section{References}

American Statistical Association. (2019). ASA newsroom. Retrieved from https://www.amstat. org/ASA/Newsroom.aspx

Caddell, M. (2007). Private schools and political conflict in Nepal. In P. Srivastava \& G. Walford (Eds.), Private schooling in less economically developed countries: Asian and African perspectives (pp. 187-207). Oxford, United Kingdom: Symposium Books.

Curriculum Development Centre. (2007). National curriculum framework for school education in Nepal, 2007. Bhaktapur: Government of Nepal, Ministry of Education and Sports.

Franklin, C., Kader, G., Mewborn, D., Moreno, J., Peck, R., Perry, M., \& Scheaffer, R. (2007). Guidelines for assessment and instruction in statistics education (GAISE) report: A pre-K-12 curriculum framework. Alexandria, VA: American Statistical Association. Retrieved from https://www.amstat.org/asa/files/pdfs/GAISE/GAISEPreK-12_Full.pdf

Jones, D. L., Brown, M., Dunkle, A., Hixon, L., Yoder, N. \& Silbernick, Z. (2015). The statistical content of elementary school mathematics textbooks. Journal of Statistics Education, 23(3). Retrieved from http://jse.amstat.org/v23n3/jones.pdf

Jones, D. L. \& Jacobbe, T. (2014). An analysis of the statistical content in textbooks for prospective elementary teachers. Journal of Statistics Education, 22(3). Retrieved from http://jse.amstat.org/v22n3/jones.pdf

Lamichhane, B. R. (2017). Recent trends of early grade mathematics curricula. International Journal of Engineering, Pure and Applied Sciences, 2(3), 92-99.

Lithner, J. (2008). A research framework for creative and imitative reasoning. Educational Studies in Mathematics, 67(3), 255-276. https://doi.org/10.1007/s10649-007-9104-2

Mainali, B. R., and Heck, A. (2017), Comparison of traditional instruction on reflection and rotation in a Nepalese high school with an ICT-rich, student-centered, investigative 
approach. International Journal of Science and Mathematics Education, 15(3), 487-507.

Ministry of Education (1971). The national education system plan for 1971-76. Ministry of Education, His Majesty's Government of Nepal.

Ministry of Education. (2009). Primary education curriculum grade 4-5. Bhaktapur:

Curriculum Development Centre, Ministry of Education, Nepal.

Ministry of Education. (2010). Education Information: A glimpse 2010. Kathmandu:

Monitoring, Evaluation and Supervision Division, Ministry of Education, Nepal.

Ministry of Education. (2012). Basic education curriculum grade 6-8. Bhaktapur: Curriculum Development Centre, Ministry of Education, Nepal.

Ministry of Education. (2014). Secondary education curriculum grade 9-10. Bhaktapur:

Curriculum Development Centre, Ministry of Education, Nepal.

Ministry of Education. (2016). School sector development plan, 2016-2023. Bhaktapur: Government of Nepal, Ministry of Education.

Pepin, B., \& Haggarty, L. (2001). Mathematics textbooks and their use in English, French, and German classrooms: A way to understand teaching and learning cultures. ZDM, 33(5), 158-175.

Robitaille, D. F., \& Travers, K. J. (1992). International studies of achievement in mathematics. In D. A. Grouws (Ed.), Handbook of research on mathematics teaching and learning (pp. 687-723). Reston, VA: National Council of Teachers of Mathematics.

Thapa, A. (2011). Does private school competition improve public school performance? The case of Nepal (Doctoral dissertation). Retrieved from ProQuest Dissertations \& Theses Global database. (Accession Order No. AAT 3454029)

Törnroos, J. (2005). Mathematics textbooks, opportunity to learn, and student achievement. Studies in Educational Evaluation, 31, 215-327.

Valverde, G. A., Bianchi, L. J., Wolfe, R. G., Schmidt, W. H., \& Houang, R. T. (2002). According to the book: Using TIMSS to investigate the translation of policy into practice through the world of textbooks. Boston: Kluwer Academic Publishers.

Wagley, M. P., Sharma, T. N., Koirala, B. N., Ramos, S. Y., Taylor, P. C., Luitel, B. C., . . . Poudel, K. P. (2008). Developing culturally contextualised mathematics resource materials: Capturing local practices of Tamang and Gopali communities. Kathmandu: United Nations Educational, Scientific, and Cultural Organization Office. Retrieved from https://researchrepository.murdoch.edu.au/id/eprint/37084/1/tamal\%20and\%20 gopali.pdf

Wood, Hugh B. (1959). Development of education in Nepal. Educational Leadership, 16(7), 429-433.

Appendix: Textbook Series in the Sample

Curriculum Development Centre. (2075 BS / 2018 AD). My mathematics, grades 4-10. Bhaktapur: Government of Nepal, Ministry of Education, Curriculum Development Centre.

Khatakho, N. B. (2074 BS / 2017 AD). Perfect mathematics, class 9 (Revised ed.). Kathmandu: 
Vidyarthi Prakashan (P.) Ltd.

Khatakho, N. B. (2075 BS / 2018 AD). Perfect mathematics, classes 4-8 (Revised ed.). Kathmandu: Vidyarthi Prakashan (P.) Ltd.

Khatakho, N. B. (2075 BS / 2018 AD). Perfect mathematics, class 10 ( $3^{\text {rd }}$ ed.). Kathmandu: Vidyarthi Prakashan (P.) Ltd.

Pant, O. N., Kadel, M. P., Mathema, R. K., Lama, U., Ghimire, A. P., Ngakhusi, R., Dangol, S., Shah, B. \& Khaniva, G. R. (2017). Green mathematics 6-10. Kathmandu: Green Books.

Pant, O. N., Kadel, M. P., Mathema, R. K., Lama, U., Ghimire, A. P., Ngakhusi, R., Dangol, S., Shah, B. \& Khaniva, G. R. (2018). Green mathematics 4 \& 5 ( $2^{\text {nd }}$ ed.). Kathmandu: Green Books.

Shrestha, H. B. (2016). MathPlus, book 9. Kathmandu: Ekta Books.

Shrestha, H. B. (2017). MathPlus, book 8 ( $2^{\text {nd }}$ ed.). Kathmandu: Ekta Books.

Shrestha, H. B. (2017). MathPlus, book 10. Kathmandu: Ekta Books.

Shrestha, H. B. (2018). New creative mathematics, books 4-7. Kathmandu: Ekta Books.

Shrestha, S., Karki, S., \& Bhandari, R. (2072 BS / 2015 AD). Functional mathematics, books 4, 6,7 \& 8. Kathmandu: Prasiddha Prakashan Pvt. Ltd.

Subedi, B. R. (Ed.), Shrestha, S., Karki, S., Bhandari, R., Koirala, R., \& KC, T. (2074 BS / 2017 AD). Functional mathematics, books 5, 9, \& 10. Kathmandu: Prasiddha Prakashan Pvt. Ltd. 